\title{
Article \\ Numerical Investigation on the Formation and Penetration Behavior of Explosively Formed Projectile (EFP) with Variable Thickness Liner
}

\author{
Dong Yang ${ }^{1,2, *}$ and Jiajian Lin ${ }^{1, *}$ \\ 1 Department of Mechanical Engineering, Anhui University, Hefei 230601, China \\ 2 Anhui Province Key Laboratory of Aviation Equipment Testing, Monitoring and Reverse Engineering, Wuhu \\ State-Owned Machinery Factory, Wuhu 241007, China \\ * Correspondence: yangdong@ahu.edu.cn (D.Y.); jjlin@ahu.edu.cn (J.L.)
}

check for updates

Citation: Yang, D.; Lin, J. Numerical Investigation on the Formation and Penetration Behavior of Explosively Formed Projectile (EFP) with Variable Thickness Liner. Symmetry 2021, 13, 1342. https://doi.org/10.3390/ sym 13081342

Academic Editor: Sergei D. Odintsov

Received: 29 June 2021

Accepted: 23 July 2021

Published: 25 July 2021

Publisher's Note: MDPI stays neutral with regard to jurisdictional claims in published maps and institutional affiliations.

Copyright: (c) 2021 by the authors. Licensee MDPI, Basel, Switzerland. This article is an open access article distributed under the terms and conditions of the Creative Commons Attribution (CC BY) license (https:/ / creativecommons.org/licenses/by/ $4.0 /)$.

\begin{abstract}
Explosively formed projectiles (EFPs) are widely used in civil applications and the military field for their excellent impact performance. How to give full play to the energy accumulation effect of explosives and improve the penetration performance has become the main problem of EFP design. The aim of the present study was to investigate the effect of liner structure on EFP formation and its penetration behavior. In order to achieve this, a finite element (FE) model was first established on the basis of the Lagrange and ALE method. Then, formation and penetration performance tests of EFP were performed to verify the validity and feasibility of the proposed FE model, where the configuration, velocity of EFP, and penetration diameter left on the target plate were compared. Finally, by using the proposed FE model, the entire process of the formation and penetration behavior of EFP with axial symmetrical variable thickness liners were analyzed, where spherical-segment liners with uniform and non-uniform thickness were developed. The results were drawn as follows: the numerical simulation error of EFP velocity was less than $5 \%$, and the simulated penetration diameter was compared to the $8.6 \%$ error obtained from the experimental method. It demonstrated that the proposed FE model had higher prediction precision. After the explosive was detonated, a forward-folding EFP was formed by the liner with a thin edge thickness, while the EFP formed by the liner with uniform thickness had a backward-folded configuration. It was also found that the liner with a thin edge thickness gave the largest steady velocity of EFP, and it was the lowest by using the liner with uniform thickness. There were two types of loads generated after the formation of an EFP, those were shock wave loading and an EFP, both causing damage in the target plate during the process of an EFP's penetration into it. The shock wave induced by liners with non-uniform thickness caused higher damage in the target plate, the maximum value of stress was reached at about 4.0 GPa. The forward-folding EFP formed by the liner with the thinnest edge thickness had the largest penetration ability. The backward-folded EFP, owing to the hollow structure, had the worst penetration ability, which failed to penetrate the target plate.
\end{abstract}

Keywords: numerical investigation; explosively formed projectile (EFP); formation and penetration behavior; axial symmetrical variable thickness liner

\section{Introduction}

Shock waves from the detonation of a high explosive can be used to deform and warp a liner of ductile metal, forming explosively formed projectiles (EFPs) [1]. EFP is widely used in civil applications and the military field for its excellent impact performance. As a result, there is a high demand on the penetration ability of an EFP. However, it is widely accepted that the parameters such as configurations [2,3], materials [4,5], and detonation conditions [6,7] significantly affect the formation and performance of EFPs. Miller [8] studied the shaped charge parameters that might have a significant effect on the shape and velocity of the explosively formed hypervelocity projectile, and obtained 
stable projectiles in the range of velocities above $10 \mathrm{~km} / \mathrm{sec}$. Brown et al. [9] designed three kinds of shaped charges and made them available for penetrating long line-of-sight targets. Kleiser et al. [10] investigated various confinement conditions to induce non-concentric liner collapse conditions and produce planar jet structures. The effects of the position, timing, and number of detonation points on the formation of the EFP were studied by $\mathrm{Li}$ et al. [11]. They found that the stable flight velocity of the projectile increased with the number of detonation points.

A generic EFP is mainly composed of the casing, high explosives, and the liner. The liner is usually in the shape of spherical segment, hemispheric segment, saucer or arc-cone with large angles and is considered highly dominant in the EFP formation. Using liners with different geometric shapes and materials could lead to distinct EFP characteristics, which inevitably result in dissimilar penetration performances. In order to observe this difference, several studies were performed to determine the formation mechanism of EFP and penetration performance of different liners against various targets. Wu et al. [12] studied the whole process of formation, flying, and penetration of EFP using a 3D-coupled hydrocode of LS_DYNA and the results showed that the shape of the liner combining arc and cone gave a high penetration ability to the EFP. Three different shapes of a charge liner, namely, conical, hemispherical, and spherical-segment, were proposed by Zhang et al. [13] to investigate their effect on the damage response of a plate in an underwater explosion. Yang et al. [14] designed a kind of spherical liner with variable wall thickness, which was used to penetrate the water-bearing composite armor structure with large spacing. The research results showed that the penetration ability of EFP mainly depends on the diameter of the projectile. Long et al. [15] investigated, both numerically and experimentally, the formation and penetration of an EFP warhead with double-layer liners. The results showed that the EFP warhead with double-layer liners can form a large aspect ratio (length-todiameter ratio) penetrator with good flight characteristics and terminal effects. Bender et al. [16] found that the kinetic energy of the projectile increased with the aspect ratio up to a maximum of 1.5. Two types of sintered powder liners, namely liners of the shape of a spherical surface sector and the conical liners with an open apex angle, were chosen by Borkowski to investigate the formation and penetration efficiency of EFP charges [17].

Some authors have developed finite element (FE) models to investigate the final shape, mass, velocity, flight stability, and penetration performance of an EFP. Han et al. [18] used AUTODYN software to investigate the formation and penetration processes of $\mathrm{Ta} / \mathrm{Zr}$ liner with various thickness ratios of inner and outer liners. Using the FE method, Pappu et al. [19] tested several EFPs with three different liner materials, namely copper, iron, and tantalum. Both Johnson-Cook and Zerilli-Armstrong constitutive models were used for each material, and the aim was to decide which one is the most suitable. The results showed that the Zerilli-Armstrong constitutive model led to better results for tantalum projectiles, while for iron and copper projectiles, the Johnson-Cook (JC) constitutive model exhibited better results. The reason for this is that the JC model considered a thermal softening term. Iron and copper have a low melting temperature and high thermal softening component, whereas tantalum has a high melting temperature and low thermal softening component. Wu et al. [12] modeled the formation and penetration processes of EFP using an arbitrary Lagrange-Eulerian (ALE) method. The effect of air drag on EFP flight was considered through an attenuation rate equation, which was fitted on the basis of experimental data. The similarity theory was also used in projectile velocity analysis, which is a method that assumes that the simulated EFP has the same shape structure as the tested EFP and they have the same initial velocity before penetrating. The literature review demonstrated that the FE model can accurately determine the entire process of the formation and penetration behavior of EFP.

The main aim of the present study was to simulate the entire process of the formation and penetration behavior of EFP with different liner structures. First, a FE modeling process was proposed in detail for simulating the formation and penetration behavior of EFP. Second, formation and penetration performance tests of EFP were performed to verify 
the validity and feasibility of the proposed FE model. Third, FE models for three cases of shaped charges with variable thickness liners were established to simulate the process beginning with detonation to the EFP penetration, and the effects of liner structure on EFP formation and its penetration behavior were analyzed.

\section{Finite Element Modeling}

\subsection{Geometry and Boundary Conditions}

Accurate reproduction of the geometrical configurations and boundary conditions is a prerequisite for FE models. The geometrical configuration of an EFP is shown in Figure 1 with an EFP warhead of length $L=72 \mathrm{~mm}$ and liner diameter $D=72 \mathrm{~mm}$, that is, the aspect ratio is 1.0. The casing has a thickness $T=5 \mathrm{~mm}$. As shown in Figure 2, schematic representation of a liner, the liner has an axisymmetric spherical shell structure, and the thickness of the middle part is $4 \mathrm{~mm}$. The remaining dimensions of the liner, such as the outer curvature radius $S R_{1}$ and the internal curvature radius $S R_{2}$, will change according to the specific model being tested. In the present study, three kinds of liners were developed, and their specific geometric dimensions are shown in Table 1. The type II liner had a uniform thickness distribution, but the thickness of type I and III liners were non-uniform. Additionally, the type III liner had the thinnest edge thickness of all.

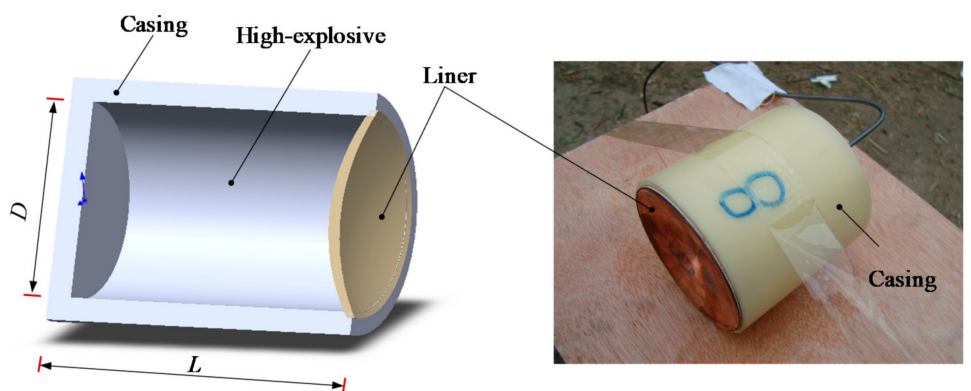

Figure 1. The geometrical configuration of an EFP.

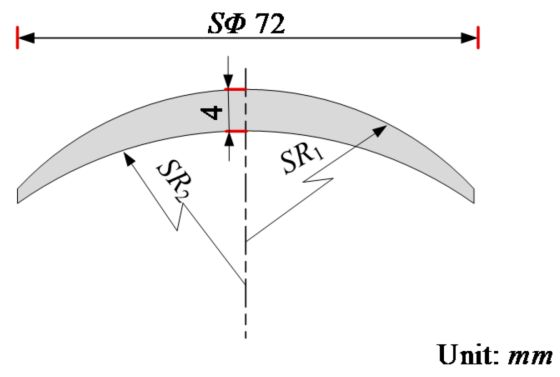

Figure 2. Schematic representation of a liner.

Table 1. Specific geometric dimensions of liners (mm).

\begin{tabular}{ccccc}
\hline Liner Type & $S_{\boldsymbol{R}_{\mathbf{1}}}$ & $\boldsymbol{S R}_{\mathbf{2}}$ & Thickness (Middle Part) & Thickness (Liner Edge) \\
\hline I & 68.0 & 76.0 & 4.0 & 2.75 \\
II & 68.0 & 68.0 & 4.0 & 4.0 \\
III & 68.0 & 90.0 & 4.0 & 1.2 \\
\hline
\end{tabular}

In the simulation, the master-slave segments approach was applied to define the contact between the liner and the dynamite, which is a specific contact algorithm that can make model surface sliding. With this approach, the pressure value is interpolated and transferred to the contacting components, resulting in their acceleration and subsequent deformation [20]. Therefore, the master-slave segments approach was adapted to model the contact behaviors between products of detonation and the remaining components of 
the EFP. In consideration of an axially symmetrical structure of the EFP, the symmetry boundary conditions were used in the FE models for the sake of simplicity.

The computational models contained three parts: EFP, air, and target plate, where the thickness of the target plate was $30 \mathrm{~mm}$. The fluid-solid coupling computing method is considered in FE models. The liner and the target are meshed with the Lagrange algorithm, and the high explosive and the air are meshed with the Eulerian algorithm and ALE technique, respectively. For the meshing algorithm, a fine mesh size produces more accurate results but requires longer time consumption in comparison with coarse meshing simulations. In the present study, the uniform square mesh sizes of $0.3 \mathrm{~mm}$ were selected based on the results of mesh sensitivity studies, which were carried out by Agu [21] and Elshenawy [22]. The high explosive was initiated at the center point of the back of EFP, and the one-point initiation method was adopted.

Due to the expansive computational costs to simulate the entire process of the deformation and penetration of the EFP, a simplified model was developed to simulate a flight distance of $24 \mathrm{~cm}$ of EFP to study its formation process. The output result was recorded every $2 \mu \mathrm{s}$. All of the above processes were performed with the finite element analysis software LS-DYNA. Schematic of the FE model to simulate the formation and penetration behavior of EFP is shown in Figure 3.

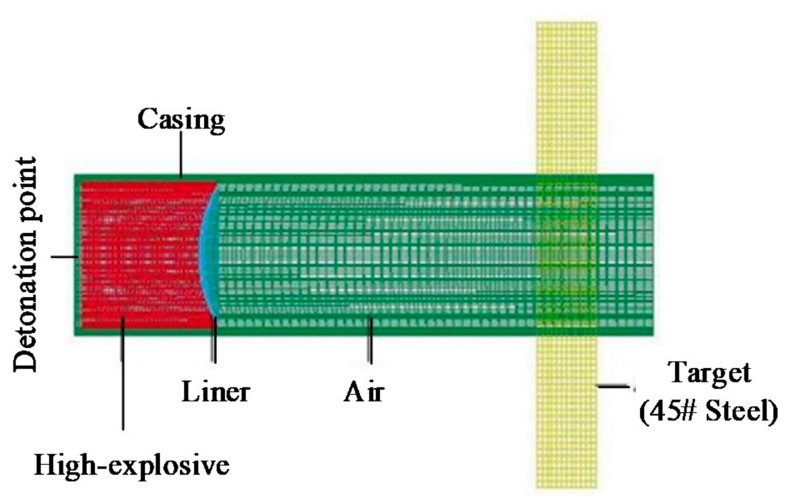

Figure 3. Simulation model of EFP warhead and steel target.

\subsection{Materials Modeling}

The components in the FE model were made up of different kinds of materials. The materials of the liner and target plate were copper and 45\# steel, respectively. The high explosive was 8701 dynamite.

The formation and penetration of EFP is a complex thermal-mechanical coupling process, where large strain, large strain, rate and high temperature occur. An accurate constitutive model used is the guarantee of a successful simulation. The Johnson-Cook constitutive model, expressed by Equation (1), was applied in the present study as it considers the factors of strain, strain rate, and temperature, simultaneously [23].

$$
\bar{\sigma}=\left[A+B \bar{\varepsilon}^{n}\right] *\left[1+C \ln \left(\frac{\dot{\bar{\varepsilon}}}{\dot{\overline{\varepsilon_{0}}}}\right)\right] *\left[1-\left(\frac{T-T_{r}}{T_{m}-T_{r}}\right)^{m}\right]
$$

where $A, B, C, n$, and $m$ are the yield stress, the hardening modulus, the strain-rate coefficient, the hardening exponent, and the thermal softening coefficient, respectively. $\bar{\sigma}$ and $\bar{\varepsilon}$ are the equivalent stress and plastic strain, $\dot{\bar{\varepsilon}}$ and $\dot{\overline{\varepsilon_{0}}}$ are the equivalent and reference strain rate. The parameters $T, T_{m}$, and $T_{r}$ are current temperature, melting temperature of workpiece material, and room temperature, respectively Table 2.

The Johnson-Cook constitutive model parameters of copper (liner) are specified in 
Table 2. Johnson-Cook constitutive model parameters of copper (liner) [23].

\begin{tabular}{ccccc}
\hline $\mathbf{A}(\mathbf{M P a})$ & $\mathbf{B}(\mathbf{M P a})$ & $\mathbf{C}$ & $\mathbf{m}$ & $\mathbf{n}$ \\
\hline 90 & 292 & 0.025 & 1.09 & 0.31 \\
\hline
\end{tabular}

The material type $8(*$ MAT_HIGH_EXPLOSIVE_BURN $)$ in LS-DYNA was used to model the detonation of high explosive 8701 dynamite. It allows modeling the detonation of a high explosive by three parameters, including mass density, detonation velocity, and Chapman-Jouget pressure [24]. The target plate material 45\# steel was modeled using type 3 material model (*MAT_PLASTIC_KINEMATIC) in LS-DYNA [25]. The reason is that this model is suited to model isotropic and kinematic hardening plasticity with the option of including rate effects. In EFP penetration calculation, element erosion can be used to remove elements that have reached the critical damage [26]. The FS variable (failure strain for eroding elements) in the plastic-kinematic model was used to control the material failure in the present study. The air elements take the null material model, and its input data mass density was $1.29 \times 10^{-3} \mathrm{~g} / \mathrm{cm}^{3}$.

The variables in the high explosive burn material model of 8701 dynamite and the material property input data of the plastic-kinematic model for 45\# steel are listed in Table 3.

Table 3. Material property input data of 8701 dynamite and 45\# steel [12].

\begin{tabular}{cccc}
\hline 45\# Steel Parameters & Values & 8701 Dynamite Parameters & Values \\
\hline Mass density $\left(\mathrm{g} / \mathrm{cm}^{3}\right)$ & 7.83 & Mass density $\left(\mathrm{g} / \mathrm{cm}^{3}\right)$ & 1.68 \\
Young's modulus $(\mathrm{GPa})$ & 207 & Detonation velocity $(\mathrm{cm} / \mu \mathrm{s})$ & 0.88 \\
Poisson's ratio & 0.3 & Chapman-Jouguet pressure $(\mathrm{GPa})$ & 37 \\
Yield stress $(\mathrm{GPa})$ & 0.5 & & \\
Tangent modulus $(\mathrm{GPa})$ & $2.07 \times 10^{-2}$ & & \\
Hardening parameter & 1.0 & & \\
Failure strain for & 0.4 & & \\
eroding elements & & & \\
\hline
\end{tabular}

The formation and penetration process of EFP is composed of isotropic pressure and viscous shear stress. The viscous shear stress can be ignored, as the gas viscosity is very poorly equivalent. The pressure of 8701 dynamite, copper (liner), and air can be presented with the Jones-Wilkins-Lee (JWL) equation of state (EOS), the Mie-Gruneisen EOS, and the linear polynomial EOS, respectively.

The JWL EOS [27] for high explosive 8701 is expressed as

$$
p=A_{1}\left[1-\frac{\omega}{R_{1} V}\right] e^{-R_{1} V}+B_{1}\left[1-\frac{\omega}{R_{2} V}\right] e^{-R_{2} V}+\frac{\omega E}{V}
$$

The JWL EOS relates pressure $p$ with relative volume $V$ and the energy per unit volume $E$. Constants $A_{1}, B_{1}, R_{1}, R_{2}$, and $\omega$ are the pressure coefficients, the first and second eigenvalues, and the fractional part of the adiabatic exponent, respectively [28].

The Mie-Gruneisen equation of state with cubic shock velocity-particle velocity defines the pressure as

$$
\begin{gathered}
p=\rho_{0} c_{0}^{2} \mu \Psi+\left(\gamma_{0}+a \mu\right) E \\
\Psi=\frac{2-a \mu^{2}+\left(2-\gamma_{0}\right) \mu}{2\left[1-\left(S_{1}-1\right) \mu-S_{2} \frac{\mu^{2}}{1+\mu}-S_{3} \frac{\mu^{3}}{(1+\mu)^{2}}\right]}
\end{gathered}
$$

where $\gamma_{0}$ is the Gruneisen coefficient, a is first-order energy correction factor, and $S_{\mathrm{i}}(\mathrm{i}=1, \ldots, 3)$ values are material parameters. $\mu$ is a non-dimensional coefficient based on the initial material density $\rho_{0}$ and instantaneous material density $\rho$ [29].

The linear polynomial equation of state is linear in internal energy. The pressure is given by:

$$
P=C_{0}+C_{1} \mu+C_{2} \mu^{2}+C_{3} \mu^{3}+\left(C_{4}+C_{5} \mu+C_{6} \mu^{2}\right) E
$$


where $C_{\mathrm{i}}(\mathrm{i}=0, \ldots, 6)$ values are polynomial coefficients.

The linear polynomial equation of state can be used to model air with the gamma law equation of state. This may be achieved by setting:

$$
C_{0}=C_{1}=C_{2}=C_{3}=C_{6}=0
$$

While

$$
C_{4}=C_{5}=\gamma-1
$$

where $\gamma$ is the ratio of specific heats. The pressure is then given by:

$$
p=(\gamma-1) \frac{\rho}{\rho_{0}} E
$$

Material properties for equations of state are shown in Table 4.

Table 4. Material properties for equations of state [12,30,31].

\begin{tabular}{cccccccc}
\hline Material & EOS & \multicolumn{7}{c}{ Parameters (Unit = cm, g, ms) } \\
\hline \multirow{2}{*}{8701} & \multirow{2}{*}{ JWL } & $A_{1}$ & $B_{1}$ & $R_{1}$ & $R_{2}$ & $E_{0}$ & $V_{0}$ \\
& & 8.54 & 0.062 & 4.60 & 1.35 & 0.085 & 1.0 \\
\multirow{2}{*}{ Copper } & \multirow{2}{*}{ Mie-Gruneisen } & $C$ & $S_{1}$ & $S_{2}$ & $S_{3}$ & $E_{0}$ & $V_{0}$ \\
& & 0.394 & 1.49 & 0.0 & 0.0 & 0.0 & 0.0 \\
\multirow{2}{*}{ Air } & \multirow{2}{*}{ Linear polynomial } & $C_{4}$ & $C_{5}$ & $E_{0}$ & $V_{0}$ & & \\
& & 0.4 & 0.4 & $2.50 \times 10^{-6}$ & 1.0 & \\
\hline
\end{tabular}

\section{FE Model Validation}

The numerical simulation results of the formation and penetration behavior of EFP were validated by experimental method. The simulation and experimental results, including velocity and structural shape of EFP, were compared. For penetration behavior of EFP, the diameter of the hole after impact on a $30 \mathrm{~mm}$ steel target was compared. Type III liner, as listed in Table 1, was selected for validation.

\subsection{Experimental Setup}

The test stand for the formation and penetration of EFP is shown in Figure 4. The examined EFP with Type III liner was fixed horizontally, and at the distance of $30 \mathrm{~m}$ from the EFP, on the projectile path, a 45\# steel plate with a total thickness of $30 \mathrm{~mm}$ was placed. At the distance of $10 \mathrm{~m}, 15 \mathrm{~m}, 23 \mathrm{~m}$, and $28 \mathrm{~m}$ from the EFP, there were four electronic time meters (instrument type: NLG202G-3) used for measurement of the EFP velocity on its path.

The dynamic process of EFP formation was registered using a pulse X-ray system. By this system, EFP velocity can also be determined. A sketch of the X-ray setup is presented in Figure 5. The EFP flight was recorded at $750 \mu$ s and $840 \mu$ s time delays (corresponding to the location P1 and P2 in Figure 5), counting from the detonation time. From the X-ray pictures, the shapes of the EFP at its formation phases were evaluated. Based on the EFP position for distinct times, the average projectile velocity was calculated.

A total of two sets of tests were carried out. The first group was applied to characterize the entire process of the formation and penetration behavior of EFP. After the penetration process of EFP, the penetration hole diameter left on the target plate was measured. The other group was the target missing test, which was used to get a formed EFP without the penetration process. In the target missing test, fifty EFP warheads were launched vertically into the sky and the formed EFPs were recovered. 


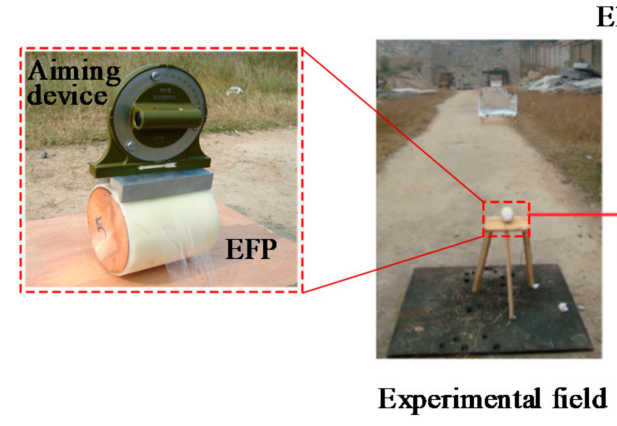

(a)
Electronic time meter $\quad 45 \#$ steel target

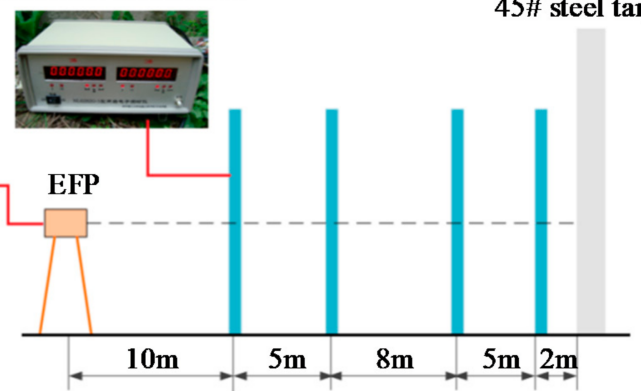

(b)

Figure 4. Experimental setup for (a) EFP device installation prior to firing and (b) EFP testing of targets and measurement of the velocity of high-speed projectiles.

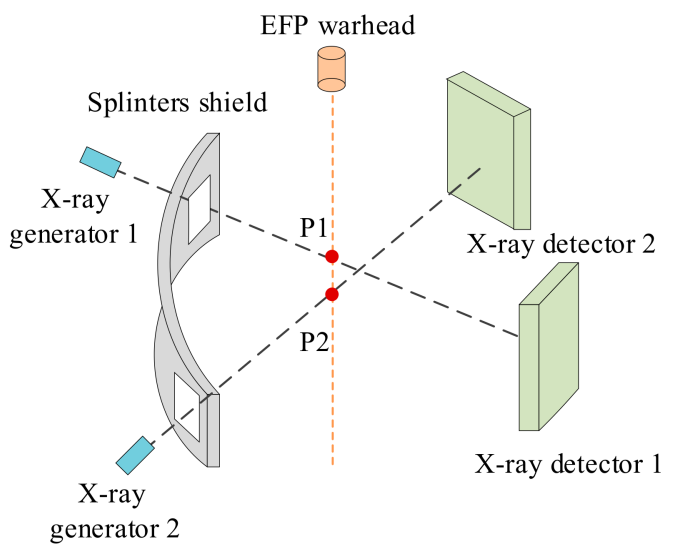

Figure 5. Sketch of the pulse X-ray setup.

\subsection{Results Comparison}

The simulated velocity of the EFP was $2103.2 \mathrm{~m} / \mathrm{s}$. From the experimental observations, it can be determined that the EFP velocity $v$ measured by electronic time meters were $2112 \mathrm{~m} / \mathrm{s}, 2134 \mathrm{~m} / \mathrm{s}, 2159 \mathrm{~m} / \mathrm{s}$, and $2070 \mathrm{~m} / \mathrm{s}$, respectively. The error of the simulated value was between $0.42 \%$ and $1.6 \%$. The numerical stable flight velocity $750 \mu$ s to $840 \mu$ s after detonation was $2200 \mathrm{~m} / \mathrm{s}$ (measured by X-ray system), leading to an estimated average numerical error of $4.4 \%$. The results in Figure 6 show the simulated velocity of the EFP against the measured values.

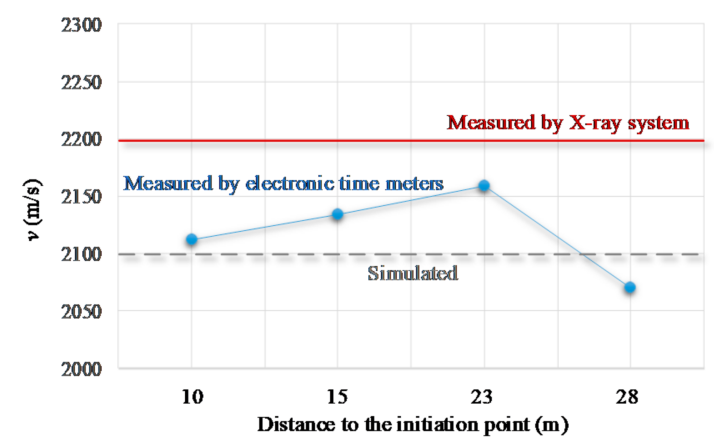

Figure 6. Velocity of EFP obtained by simulation and experiments.

A comparison of the obtained EFPs through numerical simulation, $\mathrm{X}$-ray system, and the target missing test is presented in Figure 7. It can be seen from Figure 7 that the EFP projectile obtained has a configuration with high compactness. By comparing the quality 
of recovered projectile and liner, the mass percentage of the liner mass that formed the EFP was $97 \%$. It also found that the shape of EFP obtained by the experimental method was in good agreement with the simulated one, which indicates that the proposed FE model is feasible to predict the formation process of EFP.

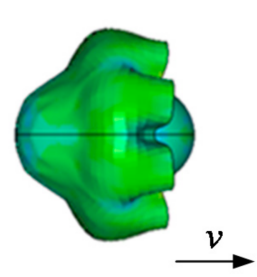

(a)

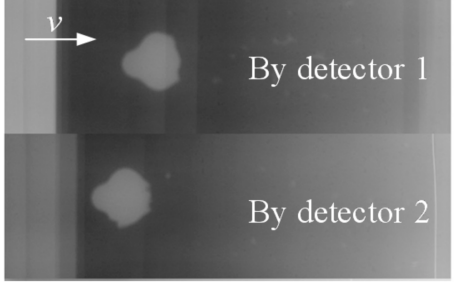

(b)

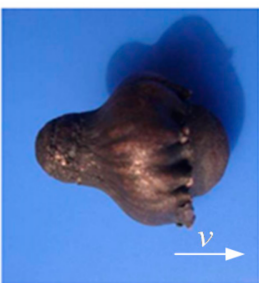

(c)

Figure 7. EFP images obtained by (a) numerical simulation, (b) X-ray system, and (c) targetmissing test.

For validation of the EFP penetration process, it was assumed that $10 \%$ would be the maximum accepted error for the FE model to be considered a reasonable approximation of the penetration test being established. Figure 8 shows the morphology of penetration holes, and it can be seen that the penetration holes were all circularly shaped. The simulated penetration diameter was $63 \mathrm{~mm}$, and the tested one was about $58 \mathrm{~mm}$. The results of the penetration hole diameter measurements show the simulated hole diameter against the $8.6 \%$ error obtained from the experimental method.

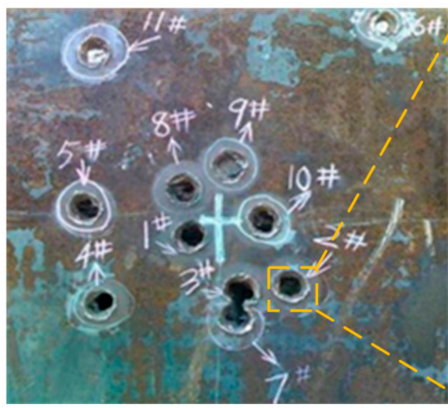

(a)

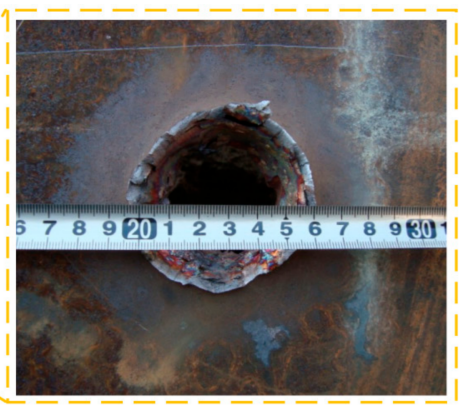

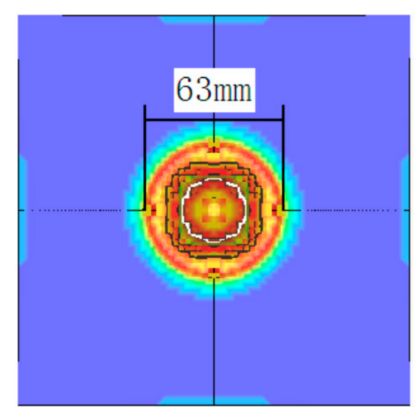

(b)

Figure 8. Penetration diameter obtained by (a) the experimental and (b) numerical method.

\section{Results and Discussion}

In this section, the proposed FE model was applied to simulate the entire process of the formation and penetration behavior of the EFP with different liner structures (as shown in Table 1), and the effects of liner structure on EFP formation and its penetration behavior were analyzed.

\subsection{Formation of EFP}

According to simulation results, three EFP with different shapes were formed under the effect of the detonation wave after the explosive was detonated. Shape distributions (contours of pressure) for three liners at specific moments and displacement are shown in Figure 9. The EFP shape at about $30 \mu$ s indicated that all of the three liners were squeezed under the effect of the detonation wave. After axial tension and radial compression of the liner, all three EFP were completely shaped at about $120 \mu \mathrm{s}$. The main geometric parameters of three completely shaped EFP are listed in Table 5. It can be seen from Table 5 that the length and diameter of EFP formed by liner III were the smallest, and the length-diameter ratio was 0.93 . The length and diameter of EFP formed by liner I were the largest, and the 
length-diameter ratio of EFP formed by liner II was the largest. A low length-diameter ratio means the high compactness of EFP.

(a)

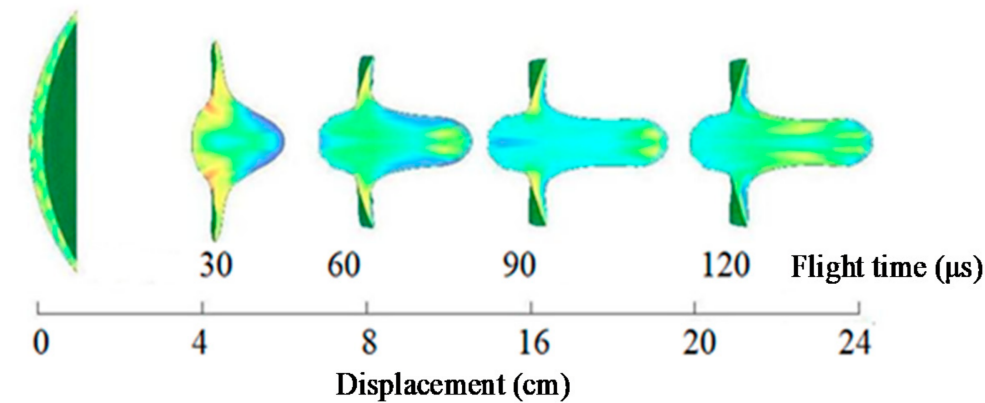

(b)

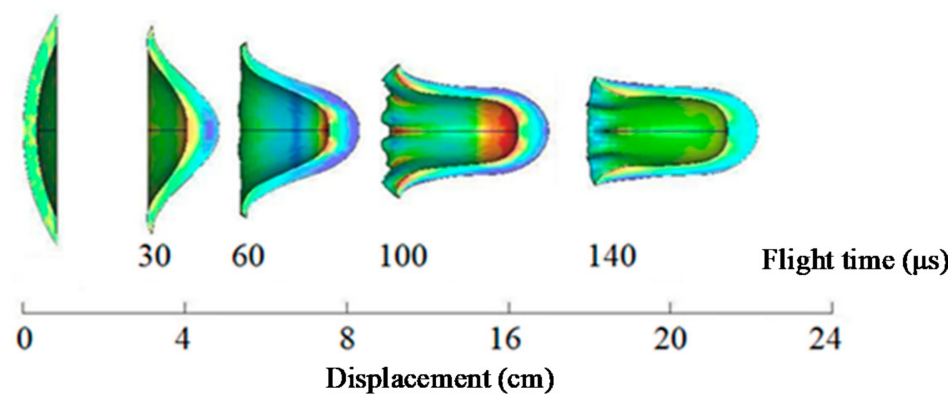

(c)

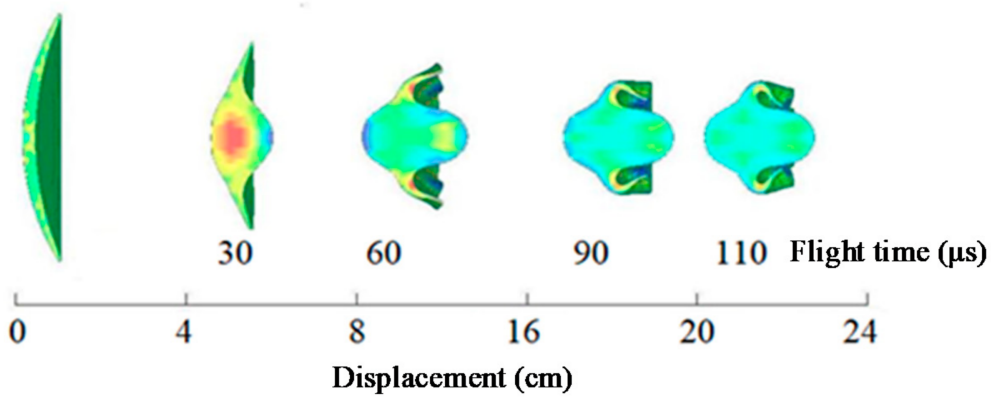

Figure 9. Shape distribution for (a) type I, (b) type II, and (c) type III liners at specific moments and displacements.

Table 5. The main geometric parameters of three completely shaped EFP.

\begin{tabular}{cccc}
\hline Liner Type & EFP Length $(\mathbf{m m})$ & EFP Diameter $(\mathbf{m m})$ & Length-Diameter Ratio \\
\hline I & 56.6 & 46.3 & 1.22 \\
II & 52.0 & 33.1 & 1.57 \\
III & 32.4 & 34.9 & 0.93 \\
\hline
\end{tabular}

It was found from Figure 9 that the EFP formed by the liners I and III were solid, but it was hollow for the type II liner. In order to ascertain the formation mechanism of EFP, the displacement-time-history relation for liners were drawn, as shown in Figure 10, where radial displacement ('X-value') of seven elements from the center to the edge of the liner were characterized.

It was ascertained from Figure 10 that radial displacement collapse of all three types of liners happened firstly at the center after the explosive was detonated, while the collapse displacement and completion time of elements at the liner center were different. For the type I liner, the collapse displacement of element at liner center (Element No. 24511) was $3.8 \mathrm{~mm}$, and the completion time was about $46 \mu \mathrm{s}$. The last element to complete the displacement collapse was the one next to the edge of the liner (Element No. 27106). The collapse displacement and completion time were $18.8 \mathrm{~mm}$ and $82 \mu \mathrm{s}$, respectively. For the element at the edge of the liner (Element No. 27181), the collapse displacement and 
completion time were $15 \mathrm{~mm}$ and $80 \mu \mathrm{s}$, respectively. Moreover, it was the larger collapse displacement at the edge of the liner that brought the EFP to an apron shape.

(a)

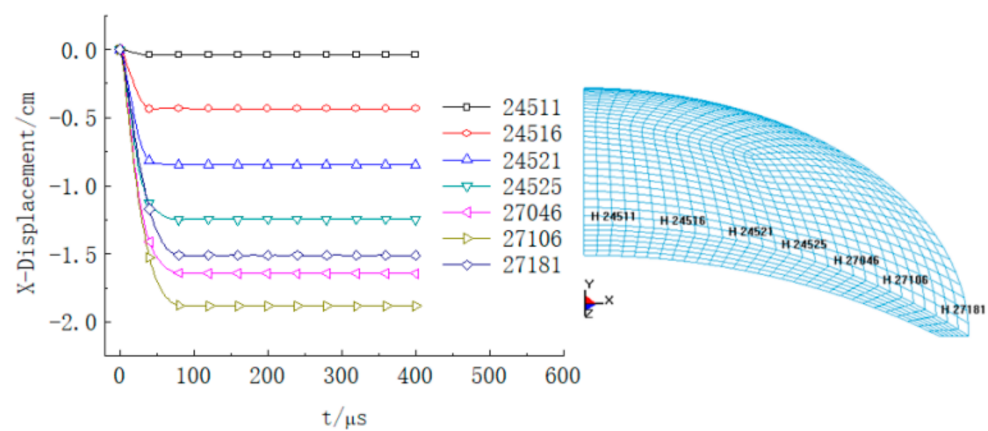

(b)

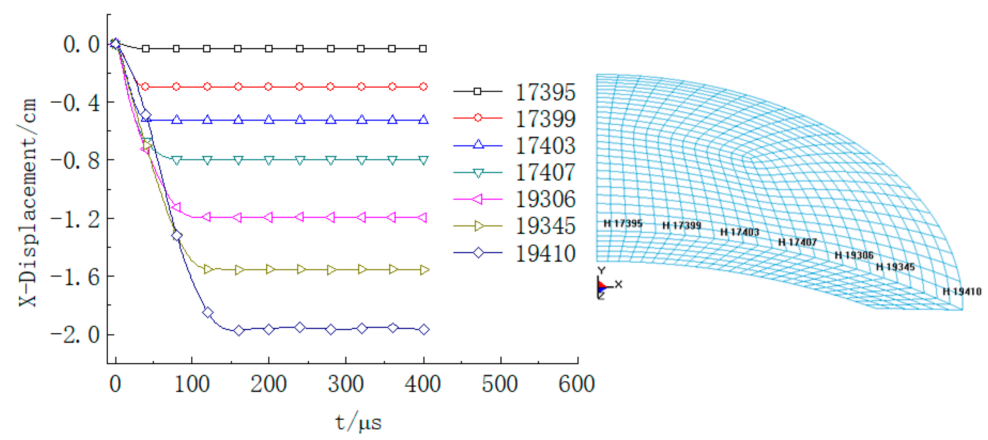

(c)

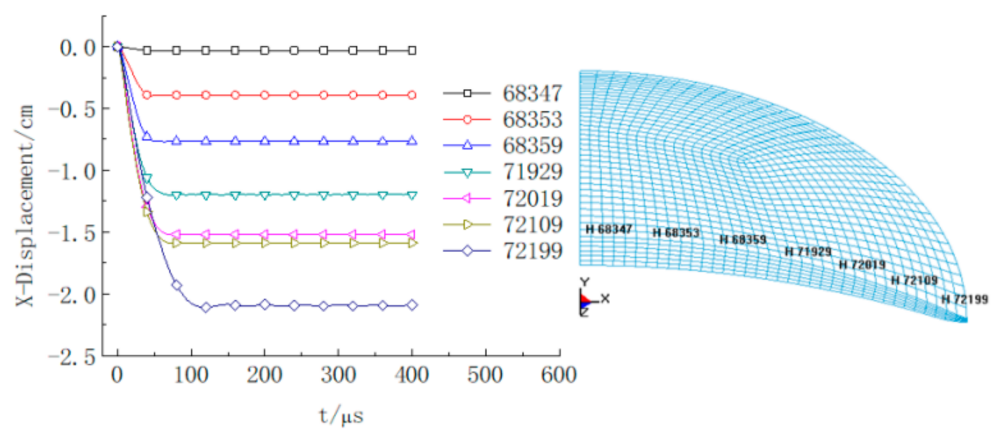

Figure 10. The displacement-time-history relation for liners (a) type I, (b) type II, and (c) type III.

In regards to type II liner, see Figure 10b, the collapse displacement and completion time of the element at the liner center were $3.3 \mathrm{~mm}$ and $34 \mu \mathrm{s}$, respectively. The last element to complete the displacement collapse was the one at the edge of the liner (Element No. 19410), and the collapse displacement and completion time were $19.6 \mathrm{~mm}$ and $118 \mu \mathrm{s}$, respectively. Also seen from Figure 10b, the collapse displacement of elements from the center to the edge of the liner was increased gradually. Finally, a pestle shape with a hollow in the tail of the EFP was formed. It was evident from Figure 10c that the displacement of elements along the radial direction of the type III liner had a similar variation with that of the type II liner, while the collapse displacement value and completion time were different. The collapse displacement and completion time of the element at the liner center (Element No. 68347) were $3.0 \mathrm{~mm}$ and $40 \mu \mathrm{s}$, and the final collapse displacement of the edged element (Element No. 72199) had a displacement of $19.8 \mathrm{~mm}$ at about $110 \mu \mathrm{s}$.

Together with the EFP formation, the EFP velocity is another one of the most significant factors. According to the numerical simulations, the EFP formed by the type III liner had the largest steady velocity, followed by type I and type II liners. Their velocities were $2103.2 \mathrm{~m} / \mathrm{s}, 1805.6 \mathrm{~m} / \mathrm{s}$, and $1478.1 \mathrm{~m} / \mathrm{s}$, respectively. The difference between the minimum and maximum values of EFP velocity was $29.7 \%$. It was found that the velocity of EFP is 
greatly affected by the liner thickness. With the decrease in the edge thickness of the liner, the velocity of EFP increased.

\subsection{Penetration Process}

After formation, the EFP began to impact the 45\# steel target plate. The thickness of the target plate was $30 \mathrm{~mm}$. Figure 11 shows the diagrams of distribution of von Mises stresses in the target plate during the penetration process of EFP. It can be seen from Figure 11 that there were two types of loads generated after the formation of an EFP, those were shock wave loading and an EFP, both causing damage in the target plate during the process of an EFP penetration into it. The initial deformation of the target plate was caused by the shock wave generated by the high explosive detonation, for the reason that the shock wave reached the target plate earlier than the EFP. The comparison of the three cases (cases I, II, and III are named by the liner type used in simulation processes) showed that the shock wave in case I reached the target plate at about $96 \mu$ s, while those in cases II and III were about $120 \mu$ s and $100 \mu$ s. In addition, the stress peaked at about 4.0 GPa in case I, which was higher than that in cases II (3.517 GPa) and III (3.981 GPa). The results demonstrated that shock wave induced by liners with non-uniform thickness would cause greater damage to the target plate.

(a)

(b)

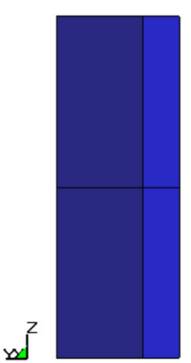

$90 \mu \mathrm{s}$

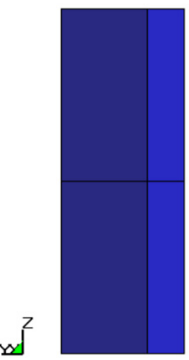

$110 \mu \mathrm{s}$

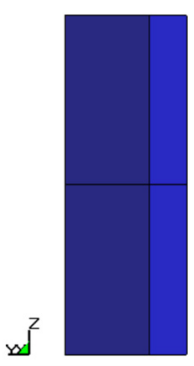

$98 \mu \mathrm{s}$

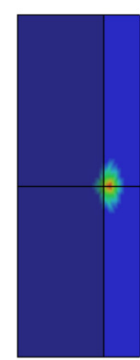

$96 \mu \mathrm{s}$

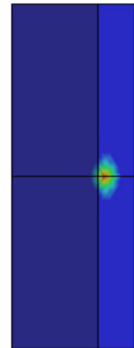

$120 \mu \mathrm{s}$

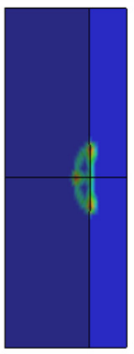

$100 \mu \mathrm{s}$

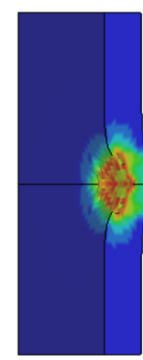

$146 \mu \mathrm{s}$

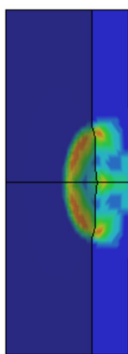

$152 \mu \mathrm{s}$

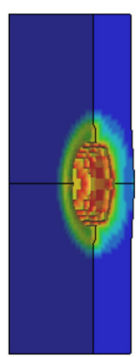

$120 \mu \mathrm{s}$

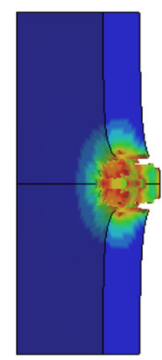

$200 \mu \mathrm{s}$

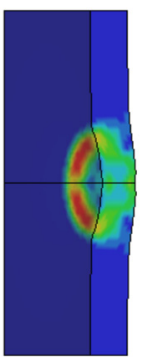

$190 \mu \mathrm{s}$

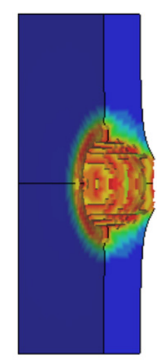

$190 \mu \mathrm{s}$

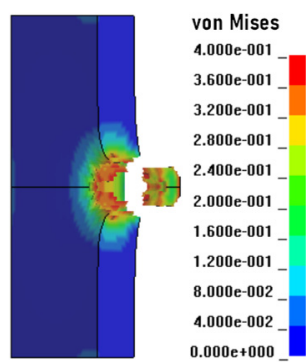

$400 \mu \mathrm{s}$

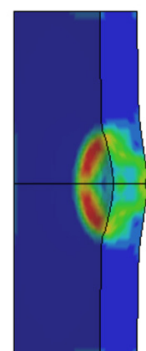

von Mises 3.517e-001 $2.814 \mathrm{e}-001$
$2.462 \mathrm{e}-001$ 2.110 e-001 $1.758 \mathrm{e}-001$ $1.407 \mathrm{e}-001$ 1.055e-001 7.034e-002 3.517e-002 $0.000 \mathrm{e}+000$

$700 \mu \mathrm{s}$

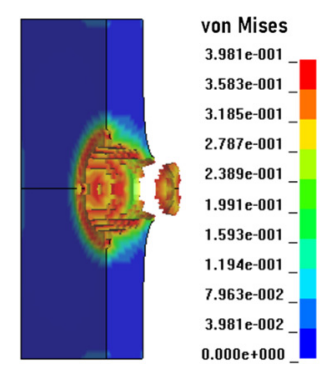

$600 \mu \mathrm{s}$

Figure 11. The penetration process of EFP for cases (a) I, (b) II, and (c) III.

After the shock wave arrived at the target plate, the EFP started penetrating it. As the EFP began to damage the target plate, the value and distribution of stress enlarged. 
Besides, it is clear that the material of the target plate was squeezed under the compression and shear stresses, which was the main failure mode of the target material. A tensioncompression coupled zone was observed in the rear of the target, as shown in Figure 12a. With the penetration depth increasing, the tension zone began to predominate, as shown in Figure 12b, which was due to the significant stretching of the material at the edge of the shear zone. The reflection of transverse waves on the back and the penetration of EFP further aggravated the development of damage. It means that there were two obvious action areas in the process of EFP penetration, one was the compression region near the front of the target plate, where the target plate was mainly subjected to compression failure, the other was the tensile zone near the back of the target plate, and the target plate in this area was mainly subjected to tensile failure. At the same stage, the penetration of EFP was impeded and the damage zone grew larger with the increase of the penetration depth.

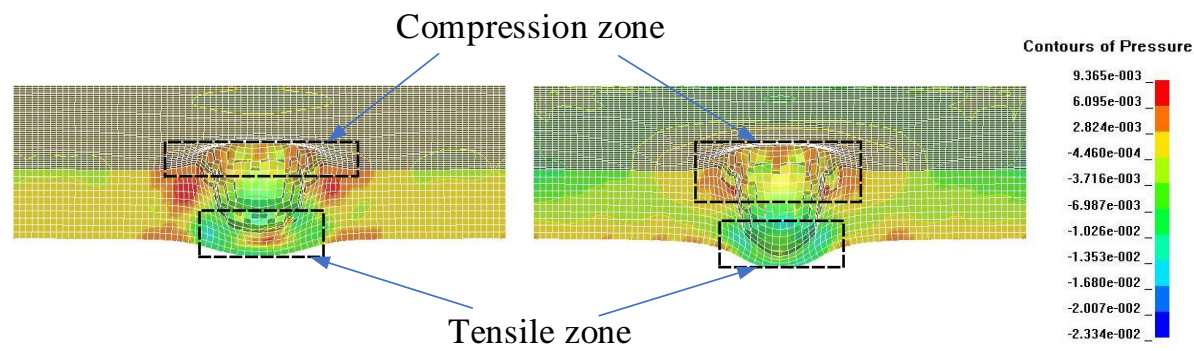

(a)

(b)

Figure 12. Load forms near the front and back of the target (e.g., case III).

The comparison of penetration for the three cases shows that the end times of penetration for cases I and III were $400 \mu \mathrm{s}$ and $326 \mu \mathrm{s}$, respectively. It means that the EFP with the type III liner penetrated the target plate faster than that with the type I liner. Besides, the EFP formed by type II liner failed to penetrate the target plate, and its final penetration depth was $11 \mathrm{~mm}$, indicating that the EFP with type II liner had the worst penetration ability. The simulation results of case II were verified experimentally, as shown in Figures 13 and 14. It can be seen from Figure 13 that the simulated EFP shape agreed with the experimental one. Figure 14 indicates that the case II experiment did not produce a full penetration. The tested depth of penetration was about $13 \mathrm{~mm}$, which was a little bit larger than the simulated value.

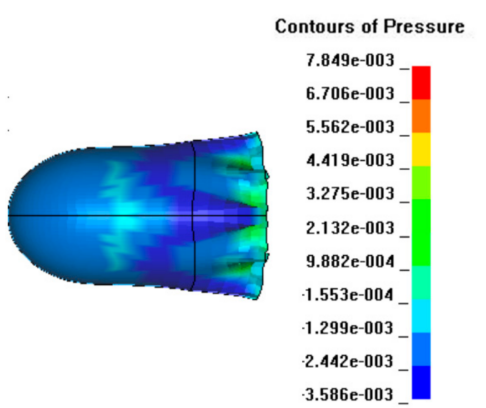

(a)

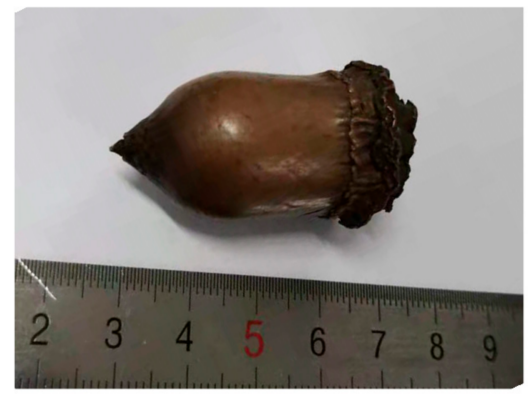

(b)

Figure 13. The shape comparison between (a) the simulation and (b) the experimental EFP formed by liner II.

The evolution of damage zones in the target plate is presented in Figure 15 in terms of penetration diameters at the front and the back of the plate. The penetration diameter at the front of the plate in case III was largest, and the diameter was $63 \mathrm{~mm}$. The diameters in cases I and II were $36 \mathrm{~mm}$ and $60 \mathrm{~mm}$, respectively. In cases I and III, diameters for the back of the plate had similar tendencies to the front, albeit being somewhat smaller. The diameters were $36 \mathrm{~mm}$ and $49 \mathrm{~mm}$, respectively. It indicates that the EFP formed by type 
III liner caused the largest damage zone for the three cases studied. There are two possible reasons for these results. On the one hand, the velocity difference for the three cases was large and the velocity in case III was the largest. On the other hand, the different EFP structures were generated under the effect of the detonation wave after the explosive. It can also be seen from Figure 9 that the shape of EFP formed by liner I was an apron-shaped projectile, and thanks to its larger axial dimension and solid structure, the EFP penetrated the target plate with a small penetration aperture, while penetration ability of this EFP was restricted because of its larger radial dimension. In case III, there was a forward-folding EFP. Due to the high compactness of this EFP, a large penetration ability was obtained. On the contrary, the EFP formed by liner II had a backward-folded configuration (pestle shaped); owing to the hollow structure, its penetration ability was the worst.

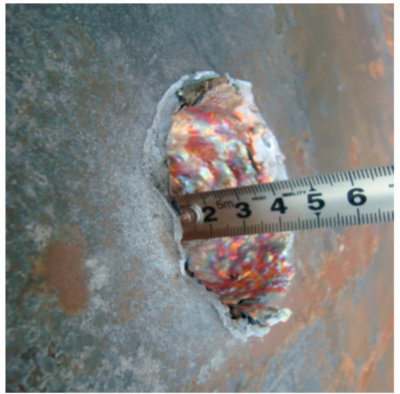

(a)

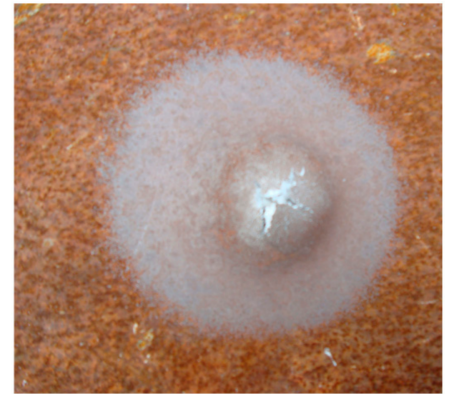

(b)

Figure 14. Damage of the target in case II, (a) front and (b) back of the target.

(a)
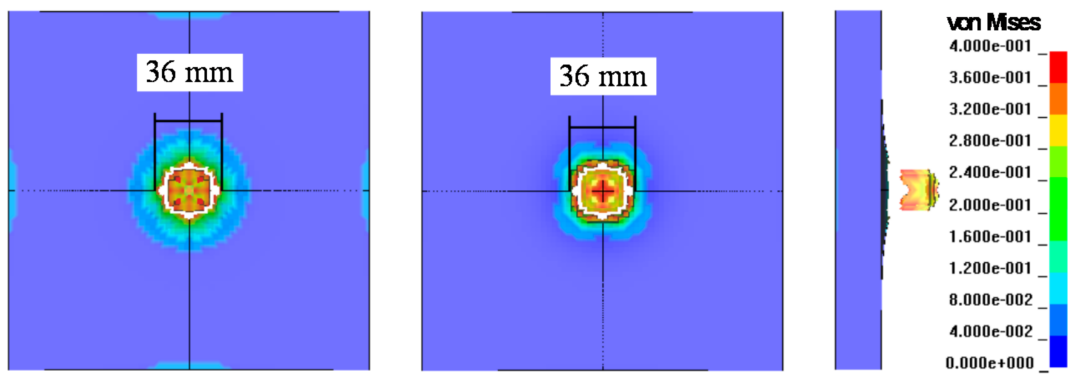

(b)
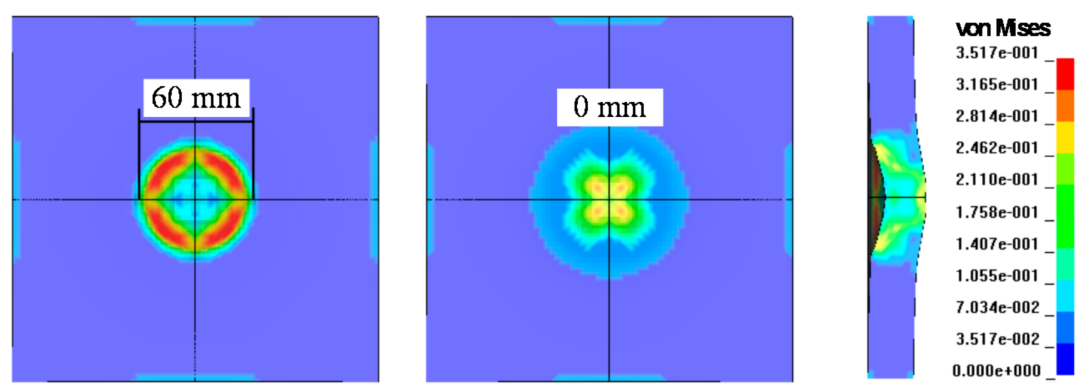

(c)
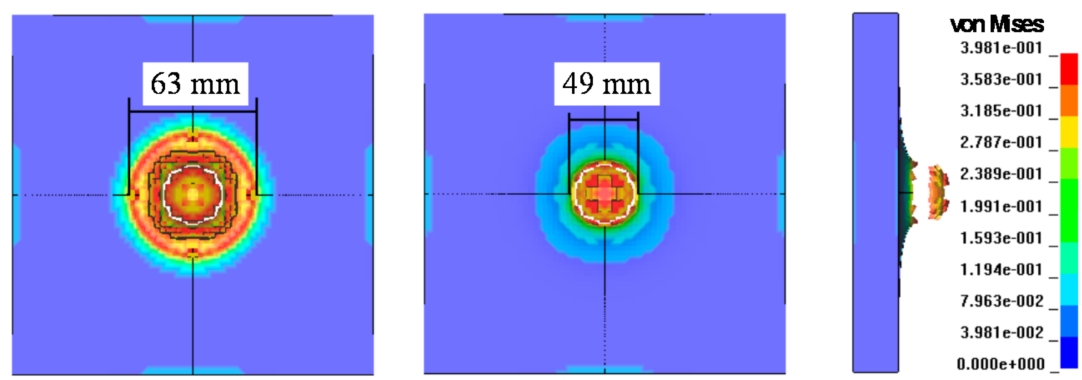

Figure 15. Damage zones in the target plate for cases (a) I, (b) II, and (c) III. 


\section{Conclusions}

In order to investigate the effect of liner structure on EFP formation and its penetration behavior, a finite element (FE) model was established on the basis of the Lagrange and ALE method. By using the proposed FE model, the entire process of the formation and penetration behavior of EFP with axial symmetrical variable thickness liners was analyzed. The main conclusion were drawn as follows.

(1) Validated by the experiments, the numerical simulation error of EFP velocity was less than $5 \%$ and the simulated penetration diameter was compared to the $8.6 \%$ error obtained from the experimental method. It demonstrated that the proposed FE model had higher prediction precision.

(2) Three kinds of liners with varying thicknesses were developed, and different shapes of EFP were formed under the effect of the detonation wave after the explosive was detonated. A forward-folding EFP was formed by the liner with a thin edge thickness. While the EFP formed by the liner with uniform thickness had a backwardfolded configuration. It was also found that a liner with a thin edge thickness gave the largest steady velocity of EFP, and it was the lowest when using the liner with uniform thickness.

(3) There were two types of loads generated after the formation of an EFP, those were shock wave loading and an EFP, both causing damage in the target plate during the process of an EFP penetration into it. The shock wave reached the target plate earlier than the EFP, which caused the initial deformation of the target plate. The shock wave induced by liners with non-uniform thickness caused greater damage in the target plate, the maximum value of stress reached at about $4.0 \mathrm{GPa}$.

(4) The material of the target plate was squeezed under the compression and shear stresses, which was the main failure mode of the target material. The reflection of transverse waves on the back and the penetration of EFP further aggravated the development of damage. The forward-folding EFP formed by the liner with the thinnest edge thickness had the largest penetration ability. The backward-folded EFP, owing to the hollow structure, had the worst penetration ability and failed to penetrate the target plate.

Author Contributions: Conceptualization, D.Y. and J.L.; methodology, D.Y. and J.L.; validation, J.L.; investigation, D.Y. and J.L.; data curation, D.Y. and J.L.; writing-original draft preparation, D.Y.; writing-review and editing, D.Y.; funding acquisition, J.L. and D.Y. Both authors have read and agreed to the published version of the manuscript.

Funding: This research was funded by The Open Foundation of National and Local Union Engineering Laboratory for Building Health Monitoring and Disaster Prevention, grant number GG19KF001, The Open Foundation of Anhui Province Key Laboratory of Building Structure and Underground Engineering, grant number JD20KF003, and China Postdoctoral Science Foundation, grant number 2020M671840.

Institutional Review Board Statement: Not applicable.

Informed Consent Statement: Not applicable.

Data Availability Statement: Not applicable.

Conflicts of Interest: The authors declare no conflict of interest.

\section{References}

1. Cardoso, D.; Teixeira-Dias, F. Modelling the formation of explosively formed projectiles (EFP). Int. J. Impact Eng. 2016, 93, 116-127. [CrossRef]

2. James, H.R.; Mellor, C.; Goff, M.G. The effect of failure diameter on the initiation of explosives by shaped charge jets Shock compression of condensed matter. AIP Conf. Proc. 2012, 1426, 291-294.

3. Ayisit, O.; Çoruh, M.M. Investigation of off-axis initiation of long L/D hemispherical shaped charge warheads. Procedia Eng. 2013, 58, 487-495. [CrossRef] 
4. Liu, J.; Long, Y.; Ji, C.; Zhong, M.S.; Liu, Q. The influence of liner material on the dynamic response of the finite steel target subjected to high velocity impact by explosively formed projectile. Int. J. Impact Eng. 2017, 109, 264-275. [CrossRef]

5. Saran, S.; Ayisit, O.; Yavuz, M.S. Experimental Investigations on Aluminum Shaped Charge Liners. Procedia Eng. 2013, 58, 479-486. [CrossRef]

6. Ma, B.; Huang, Z.H.; Guan, Z.W.; Zu, X.D.; Jia, X.; Xiao, Q.Q. Research of the axial strong magnetic field applied at the initial period of inertial stretching stage of the shaped charge jet. Int. J. Impact Eng. 2018, 113, 54-60. [CrossRef]

7. Bai, X.; Liu, J.X.; Li, S.K.; Lv, C.C.; Guo, W.Q.; Wu, T.T. Effect of interaction mechanism between jet and target on penetration performance of shaped charge liner. Mater. Sci. Eng. A 2012, 553, 142-148.

8. Miller, S. A new design criteria for explosively-formed hypervelocity projectile (EFHP). Int. J. Impact Eng. 1990, 10, 403-411. [CrossRef]

9. Brown, R.E.; Majerus, M.E.; Lewis, J.S. Building characteristics into a shaped charge to achieve unique performance requirements. Int. J. Impact Eng. 1995, 17, 121-130. [CrossRef]

10. Kleiser, G.; Lambert, D. Control of shaped charge jets through non-uniform confinement. Procedia Eng. 2015, 103, 302-309. [CrossRef]

11. Li, W.B.; Wang, X.M.; Li, W.B. The effect of annular multi-point initiation on the formation and penetration of an explosively formed penetrator. Int. J. Impact Eng. 2010, 37, 414-442. [CrossRef]

12. $\mathrm{Wu}, \mathrm{J} . ; \mathrm{Liu}, \mathrm{J} . ; \mathrm{Du}, \mathrm{Y}$. Experimental and numerical study on the flight and penetration properties of explosively-formed projectile Int. J. Impact Eng. 2007, 34, 1147-1162. [CrossRef]

13. Zhang, Z.F.; Wang, L.K.; Silberschmidt, V.V. Damage response of steel plate to underwater explosion: Effect of shaped charge liner. Int. J. Impact Eng. 2017, 103, 38-49. [CrossRef]

14. Yang, L.; Zhang, Q.M.; Yu, Y.Y. Experimental Study on the Penetration of Explosively Formed Projectile against Water-Partitioned Armor. Trans. Beijing Inst. Technol. 2009, 29, 197-200.

15. Long, Y.; Liu, J.F.; Ji, C.; Zhong, M.S.; Liu, Y.; Zhou, H. Numerical Simulation on Formation and Penetration of Double-layer Liners EFP Warhead Influenced by Multi-point Initiation. Acta Armamentarii 2016, 37, 2226-2234.

16. Bender, D.; Carleone, J. Tactical missile warheads. In: Progress in astronautics and aeronautics. Am. Inst. Aeronaut. Astronaut. 1993, 155, 367-386.

17. Borkowski, J.; Wilk, Z.; Koslik, P.; Szymanczyk, L.; Zygmunt, B. Application of sintered liners for explosively formed projectile charges. Int. J. Impact Eng. 2018, 118, 91-97. [CrossRef]

18. Han, W.; He, Y.; Shen, X.J.; Wang, C.T. Investigation of EFP Forming and Penetration of Ta/Zr Double-Layered Shaped Charge Liner. J. Ordnance Equip. Eng. 2019, 40, 163-167.

19. Pappu, S.; Murr, L.E. Hydrocode and microstructural analysis of explosively formed penetrators. J. Mater. Sci. 2002, 37, 233-248. [CrossRef]

20. Munoz, J.J. On the modeling of incompressibility in linear and non-linear elasticity with the master-slave approach. Int. J. Numer. Methods Eng. 2010, 74, 269-293. [CrossRef]

21. Agu, H.O.; Hameed, A.; Appleby-Thomas, G.J. Application of Shell Jetting Analysis to Determine the Location of the Virtual Origin in Shaped Charges. Int. J. Impact Eng. 2018, 122, 175-181. [CrossRef]

22. Elshenawy, T.; Elbeih, A.; Li, Q.M. Influence of target strength on the penetration depth of shaped charge jets into RHA targets Int. J. Mech. Sci. 2018, 136, 234-242. [CrossRef]

23. Johnson, G.R.; Cook, W.H. A constitutive model and data for metals subjected to large strains, high strain rates and high temperatures. In Proceedings of the Seventh International Symposium on Ballistics, The Hague, The Netherlands, 19-21 April 1983; pp. 51-547.

24. Zhu, F. Modeling of Blast Wave and Its Effect on the Human/Animal Body. In Basic Finite Element Method as Applied to Injury Biomechanics; Academic Press: Cambridge, MA, USA, 2018; pp. 689-701.

25. Niu, C.; Lu, Y.G.; Tao, J.L. Numerical Simulation Research for CFST Columns under Blast Load. Adv. Mater. Res. 2013, 838, 644-647. [CrossRef]

26. Justusson, B.; Pang, J.; Molitor, M.; Rassaian, M.; Pereira, M. The use of depth of penetration testing to develop element erosion parameters in LS-DYNA explicit simulations. In Proceedings of the AIAA Scitech 2019 Forum, San Diego, CA, USA, 7-11 January 2019; p. 2056.

27. Baudin, G.; Serradeill, R. Review of Jones-Wilkins-Lee equation of state. EPJ Web Conf. 2010, 10, 21. [CrossRef]

28. Urtiew, P.A.; Hayeo, B. Parametric study of the dynamic JWL-EOS for detonation products. Combust. Explos. Shock Waves 1991, 27, 505-514. [CrossRef]

29. Christou, G.A.; Young, L.R.; Goel, R.; Vechart, A.P.; Jerusalem, A. Shock attenuation of PMMA sandwich panels filled with soda-lime glass beads: A fluid-structure interaction continuum model simulation. Int. J. Impact Eng. 2012, 47, 48-59. [CrossRef]

30. Xing, B.Y.; Liu, R.Z.; Guo, R.; Chen, L.; Zhou, H.; Yang, Y.L. Influence of the embedded structure on the efp formation of compact terminal sensitive projectile. Def. Technol. 2017, 4, 84-89. [CrossRef]

31. Allahdadi, F.A.; Carney, T.C.; Hipp, J.R.; Libersky, L.D.; Petschek, A.G. High strain lagrangian hydrodynamics: A threedimensional SPH code for dynamic material response. J. Comput. Phys. 1993, 109, 67-75. 